\title{
Isotherm Study for the Biosorption of Cd (II) from Aqueous Solution by the Aquatic Weed: Ceratophyllum demersum
}

\author{
D. L. S. M. Jayarathne' ${ }^{1}$, S. Ariharan ${ }^{2}$, S. S. Iqbal ${ }^{2}$ and M. Thayaparan ${ }^{2, \#}$ \\ ${ }^{1}$ Herbal Technology Section, Industrial Technology Institute, \\ Bauddhaloka Mawatha, Colombo 7 \\ ${ }^{2}$ Department of Chemistry, Faculty of Natural Sciences, \\ The Open University of Sri Lanka, Nawala, Nugegoda \\ \#Corresponding Author: \\ Tele: 0112881304; E-mail: mthay@ou.ac.lk
}

\begin{abstract}
Owing to various anthropogenic activities our environment is being polluted especially by discharging effluents containing heavy metals. Heavy metals are nondegradable and persist for a long time in the environment. Hence they pose potential risk on the environment. Cadmium is a toxic element and cause severe damages to both animals and plants. Biosorption which is a process that utilizes dead or living biomass to sequester heavy metals is currently gaining considerable important as an alternative low cost and eco-friendly technology to remove heavy metals from aquatic media. In this study, three aquatic plants such as Eichhornia crassipes, Ceratophyllum demersum and Salvinia mollesta were screened for the biosorption of cadmium and the plant biomass was analyzed for $\mathrm{Cd}$ using Atomic Absorption Spectrometer. Ceratophyllum demersum was selected and batch experiments were carried out to examine the influence of biosorbent dosage, initial concentration of metal ion and contact time on the cadmium (II) ion adsorption. Sorption data was analyzed using linear and nonlinear regression methods of Langmuir and Freundlich isotherm models. Desorption experiment was also carried out. Biosorption of cadmium by Ceratophyllum demersum was very rapid (20 minutes) at pH 5 and at room temperature. Adsorption capacity of Ceratophyllum demersum for cadmium increased with increasing concentration of Cd ions. The nonlinear adsorption isotherm of Langmuir model did not fit well with the sorption data (high $\chi^{2}=4.58$ ). Although three linear forms (I, II and V) of Langmuir isotherm model supported the sorption data $(R 2=0.9316,0.9124$ and 0.912), however the separation factor, RL, was less than zero and also maximum adsorption capacity, qm were very low in all five linear forms. Both linear and nonlinear forms of Freundlich adsorption isotherm model exhibited a better fit with high correlation $R 2=0.92$ and low $\chi^{2}=1.95$ respectively, which indicates $a$ multilayer adsorption. Desorption experiments indicated that 0.1M EDTA, 0.1M $\mathrm{HCl}$ and 0.1M HNO3 were efficient desorbents for recovery of $\mathrm{Cd}$ (II) from the loaded biomass.
\end{abstract}

KEYWORDS: Biosorption, Cadmium, Ceratophyllum demersum, Isotherms models 


\section{Introduction}

The discharge of heavy metals into aquatic systems has become a serious problem of concern all over the world. Heavy metals are one of the most serious inorganic pollutants due to its toxicity, persistence and bioaccumulation in aquatic organisms (Esfahani et al., 2013). These pollutants are introduced into aquatic systems significantly as a result of various anthropogenic activities. Cadmium is a toxic element, non-essential for plants and animals and is usually associated with zinc in most rocks and soils (Sutherland and Venkobachar, 2013). It is widely used in the manufacture of paints, plastics, batteries and metal plating. It is known to accumulate in living organisms, especially in human kidneys and causing damage to the filtering mechanism. Thus the removal and recovery of cadmium is important to protect the environment.

Traditional treatment methods for removing heavy metals such as chemical precipitation, chemical oxidation and reduction, electrochemical methods, ion exchange and reverse osmosis are often ineffective, expensive and generate secondary wastages (Ahalya et al., 2003). More over these methods are specific to each metal and are not eco-friendly.

Biosorption has been now recognized as an effective alternate method for removing heavy metals from aqueous solutions. It can be defined as the property of certain biomass to bind and concentrate selected ions or molecules form aqueous solution (Volesky and Naja, 2007). The major advantages of biosorption over other traditional treatment methods are low cost, high efficiency of metal removal from dilute solutions, regeneration of biosorbent, possibility of metal recovery and ecofriendly.

Recently more efforts have been made to use various agricultural waste such as coconut shell (Pinoa et al., 2006), Orange peel (Pérez-Marín et al., 2007), rice husk (Dada et al., 2012), and peanut (Witek et al., 2011) as biosorbent to remove heavy metals from aqueous solution. Aquatic plants also are known to adsorb heavy metals from aqueous solutions (Huang et al., 2009; Chathuranga et al., 2012).

\section{Methodology}

\section{Preparation of Biosorbent}

Mature and healthy samples of E.crassipes, Ceratophyllum demersum and Salvinia mollesta were collected from Gampaha and Piliyandala area. Aquatic plants were washed thoroughly with tap water to remove soil particles and other impurities and then with distilled water. Plant samples were dried in air for two days then in an oven at $60{ }^{\circ} \mathrm{C}$ for 24 hours (Radojevic and Baskin, 1999). They were ground into powder. The biomass was passed through a sieve of pore size $500 \mu \mathrm{m}$ and stored in plastic containers. 


\section{Screening Experiment}

In this study three aquatic plants were screened for biosorption capacity. Biomass of each plant $(3.0 \mathrm{~g})$ was thoroughly mixed with $100 \mathrm{~cm}^{3}$ of $5.0 \mathrm{mg} / \mathrm{L}$ cadmium solution at $\mathrm{pH} 5.0$ in a conical flask. The suspension was shaken on a mechanical shaker for 3 hours at $80 \mathrm{rpm}$. Biomass was separated from the metal solution by filtering through a filter paper. The biomass washed thoroughly and subjected to Cd analysis.

\section{Dry Ashing Method}

Biomass of each plant was air dried then, oven dried at $105^{\circ} \mathrm{C}$ for 4 hours. A known weight $(2.5 \mathrm{~g})$ of each dried biomass was taken in a small crucible and placed in muffle furnace at $450{ }^{\circ} \mathrm{C}$ for 4 hours. After cooling, a drop of distilled water was added and then $5.0 \mathrm{~cm}^{3}$ of conc. $\mathrm{HNO}_{3}$ was added to the ash. The ashed sample was slowly heated on a sand bath for 30 minutes at $120-130{ }^{\circ} \mathrm{C}$. To this $5.0 \mathrm{~cm}^{3}$ of $30 \%$ $\mathrm{H}_{2} \mathrm{O}_{2}$ was added with care in small amounts to avoid possible foaming depending on sample composition. The heating was continued at that temperature until a clear solution was obtained (Hoenig et al., 1998). After cooling of sample, the solution was made up to $100.0 \mathrm{~cm}^{3}$ and analyzed for $\mathrm{Cd}$ using Atomic Absorption Spectrophotometer (Varian-AA 280FS).

\section{Investigation of the Effect of Dosage of Biosorbent}

Different dosages ( $0.05 \mathrm{~g}, 0.1 \mathrm{~g}, 0.2 \mathrm{~g}, 0.3 \mathrm{~g}, 0.4 \mathrm{~g}, 0.5 \mathrm{~g}, 1.0 \mathrm{~g}, 1.5 \mathrm{~g}$, and $2.0 \mathrm{~g})$ of biosorbent of the selected plant from screening experiment were thoroughly mixed with $100 \mathrm{~cm}^{3}$ of $5.0 \mathrm{mg} / \mathrm{L}$ cadmium solution at $\mathrm{pH} 5$ and at $29^{\circ} \mathrm{C}$ in conical flasks. The suspensions were shaken on a mechanical shaker for 180 minutes at $80 \mathrm{rpm}$. This experiment was performed in triplicates. Biomass was separated from the metal solution by filtering through a filter paper and filtrate was subjected to residual $\mathrm{Cd}$ determination by Atomic Absorption Spectrophotometer (AAS). Biomass in distilled water served as control.

\section{Investigation of the Effect of Contact Time on Cadmium Adsorption}

The biomass $(0.5 \mathrm{~g})$ of the selected plant was taken into a conical flask with $100 \mathrm{~cm}^{3}$ of $5.0 \mathrm{mg} / \mathrm{L}$ cadmium solution at $\mathrm{pH} 5.0$ and $29{ }^{\circ} \mathrm{C}$. The suspensions were shaken on a mechanical shaker at $80 \mathrm{rpm}$. The experiment was performed in triplicates and the suspensions were removed from the shaker at pre-determined time intervals (5 min, 10, 15, 20, 30, 45, 60, 90, and 120 minutes) and filtered. The filtrate was subjected to residual Cd determination by AAS. Biomass in distilled water served as control. 


\section{Investigation of the Effect of Initial Concentration of Cadmium Solution}

The biomass of $(0.5 \mathrm{~g})$ of the selected plant from the screening experiment was added to $100.0 \mathrm{~cm}^{3}$ of solution of different initial concentrations $(5,10,20,40,60$, 80,100 , and $120 \mathrm{mg} / \mathrm{L}$ ) at $\mathrm{pH} 5.0$ individually and mixed thoroughly at $29{ }^{\circ} \mathrm{C}$ in conical flasks. The suspension was shaken on a mechanical shaker for 3 hours at 80 $\mathrm{rpm}$. The experiment was conducted in triplicates. Biomass was filtered and filtrate was analyzed for Cd content by AAS.

The Sorption data from this experiment were subjected to both Linear and non linear forms (using Solver) of Langmuir and Freundlich adsorption isotherm models.

\section{Adsorption Isotherm Models}

Adsorption isotherms are mathematical models which explain the behavior of adsorption species between liquid and solid phases. Langmuir isotherm model and Freundlich isotherm model are two important isotherm models which are commonly used by researchers.

\section{Langmuir Isotherm Model}

Langmuir model assumes that all adsorbing sites are identical and the probability of a molecule to adsorb is proportional to the concentration of the adsorbate in the fluid. It also assumes that adsorbing sites are not affected by the presence of other adsorbate molecules. The curve is linear for low concentration and at high concentration the isotherm bends to form a horizontal asymptote which corresponds to the condition where all of the adsorbing sites are filled with the adsorbate.

The mathematical expression of Langmuir isotherm model is:

$$
q_{e}=\frac{q_{m} b c_{e}}{1+b c_{e}}
$$

Langmuir equation can be linearized in to five different forms as shown in Table 1.

Table 1. Linear Langmuir equations

\begin{tabular}{cc}
\hline Isotherm & Linearized Equation \\
\hline Langmuir - I & $C_{e / q_{e}}=1 / q_{m} c_{e}+1 / b q_{m}$ \\
Langmuir - II & $1 / q_{e}=1 / b q_{m} 1 / c_{e}+1 / q_{m}$ \\
Langmuir - II & $q_{e}=-1 / b q_{e} / c_{e}+q_{m}$ \\
Langmuir - VI & $q_{e} / c_{e}=-b q_{e}+b q_{m}$ \\
Langmuir - V & $1 / c_{e}=\mathrm{b} q_{m} 1 / q_{m}-\mathrm{b}$ \\
\hline
\end{tabular}


Where $\mathrm{C}_{\mathrm{e}}$ is equilibrium concentration of metal $(\mathrm{mg} / \mathrm{L}), \mathrm{q}_{\mathrm{e}}$ is the amount of the metal adsorbed $\left(\mathrm{mg} / \mathrm{g}\right.$ ) by per unit mass of the biosorbent $(\mathrm{g}), \mathrm{q}_{\mathrm{m}}$ and $\mathrm{K}_{\mathrm{L}}$ are Langmuir constants evaluated from slope and the intercept respectively of the linear plots of Langmuir.

Based on the further analysis of Langmuir equation, the dimensionless parameter of the equilibrium known as separation factor $\left(\mathrm{R}_{\mathrm{L}}\right)$ is expressed by:

$$
R_{L}=\frac{1}{1+b C_{0}}
$$

Where $\mathrm{C}_{\mathrm{o}}$ is the initial concentration of adsorbents. The $\mathrm{R}_{\mathrm{L}}$ parameter is considered as a more reliable indicator in the adsorption. There are four probabilities for the $\mathrm{R}_{\mathrm{L}}$ values.

For favorable adsorption, $0<\mathrm{R}_{\mathrm{L}}<1$

For unfavorable adsorption, $\mathrm{R}_{\mathrm{L}}>1$

For linear adsorption, $\mathrm{R}_{\mathrm{L}}=1$

For irreversible adsorption, $\mathrm{R}_{\mathrm{L}}=0$ (Huang et al., 2009).

\section{Freundlich Isotherm Model}

This model is commonly used to describe the adsorption characteristics for the heterogeneous surface. That is a multilayer adsorption can be explained by using Freundlich isotherm model.

The mathematical expression of Freundlich isotherm model is:

$$
q_{e}=K_{f} C_{e}^{\frac{1}{n}}
$$

Where $\mathrm{K}_{\mathrm{f}}$ is an indicator of adsorption capacity and ' $\mathrm{n}$ ' is adsorption intensity. The linearized Freundlich equation is expressed as follows:

$$
\log q_{e}=\log K_{f}+\frac{1}{n} \log C_{\theta}
$$

' $n$ ' in the Freundlich isotherm model indicates about the favorable condition of the adsorption. The values of ' $n$ ' in the range from 2-10 indicate good adsorption, 1-2 moderate adsorption and less than 1 indicates poor adsorption (Mirjana et al., 2012).

\section{Desorption Experiment}

For the desorption experiment, $0.5 \mathrm{~g}$ of selected aquatic plant was loaded with 50.0 $\mathrm{cm}^{3}$ of $40 \mathrm{mg} / \mathrm{L}$ cadmium solution at $\mathrm{pH}$ 5.0. This experiment was carried out at room temperature $29{ }^{\circ} \mathrm{C}$ for 20 minutes of contact time. The residual solution was 
subjected for $\mathrm{Cd}$ analysis. Cadmium loaded biomass were collected, gently washed and dried in air. Then the biomass was shaken with various desorbing agents such as $0.1 \mathrm{M}$ EDTA (Ethylenediaminetetraacetic acid), $0.1 \mathrm{M} \mathrm{HCl}$ and $0.1 \mathrm{M} \mathrm{HNO}_{3}$ solutions for 20 minutes at $80 \mathrm{rpm}$ in the room temperature $\left(29^{\circ} \mathrm{C}\right)$. Concentration of $\mathrm{Cd}^{2+}$ in the aqueous solution was determined by AAS.

\section{Results and Discussion}

\section{Screening of Biosorbents}

Ceratophyllum demersum adsorbed maximum cadmium from the aqueous solution, and it was selected as the best biosorbent (Figure 1).

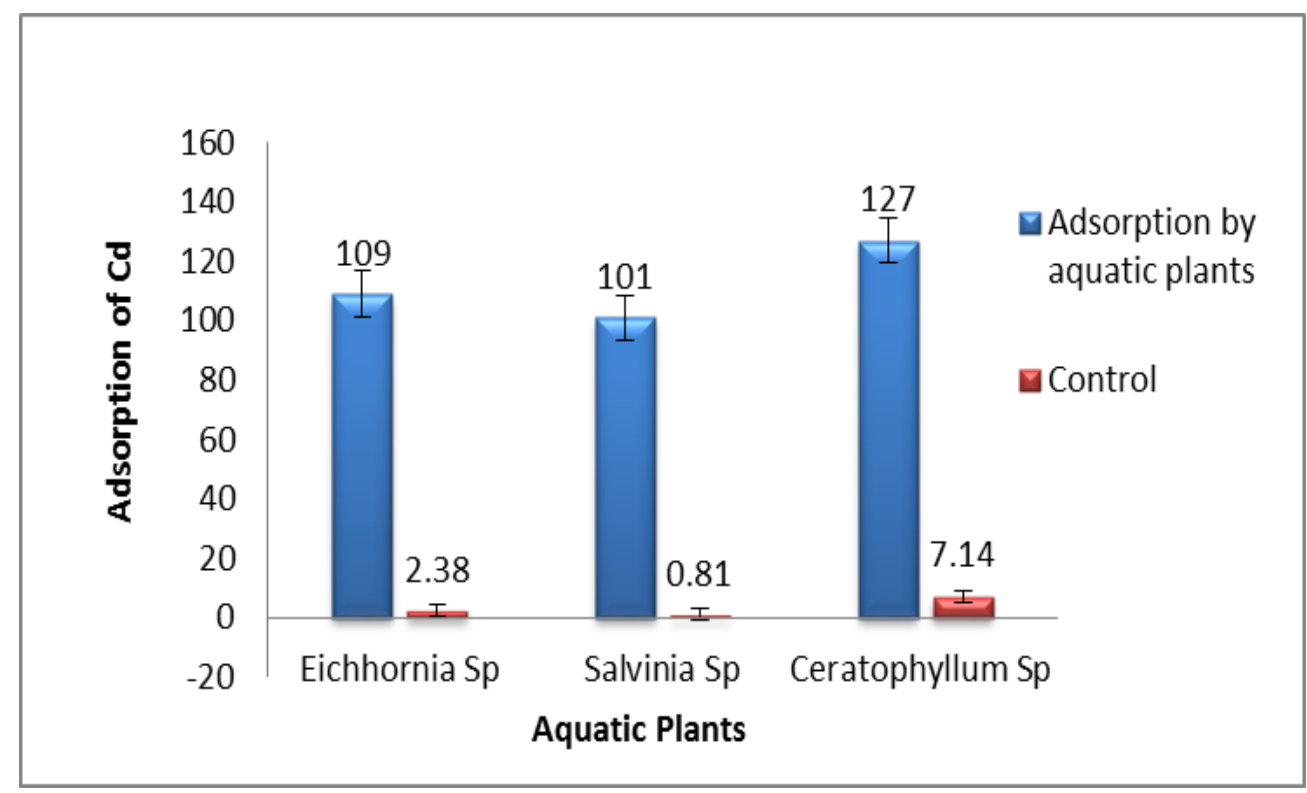

Figure 1: Adsorption of Cd by aquatic plants

\section{Effect of Biosorbent Dosage on Cadmium Adsorption}

The percentage of adsorbed cadmium by Ceratophyllum demersum increases with increasing dosage of biosorbent and reached maximum (99\%) at $1.0 \mathrm{~g}$ of dosage. Percentage of adsorption remains constant at dosage higher than $1.0 \mathrm{~g}$ (Figure 2).

When the dosage of biosorbent was increased, the surface area also increased. As a result the active sites will increase; this will lead to increase in adsorption. At dosage higher than $1.0 \mathrm{~g}$, there were not enough biosorbate molecules for available binding sites. 


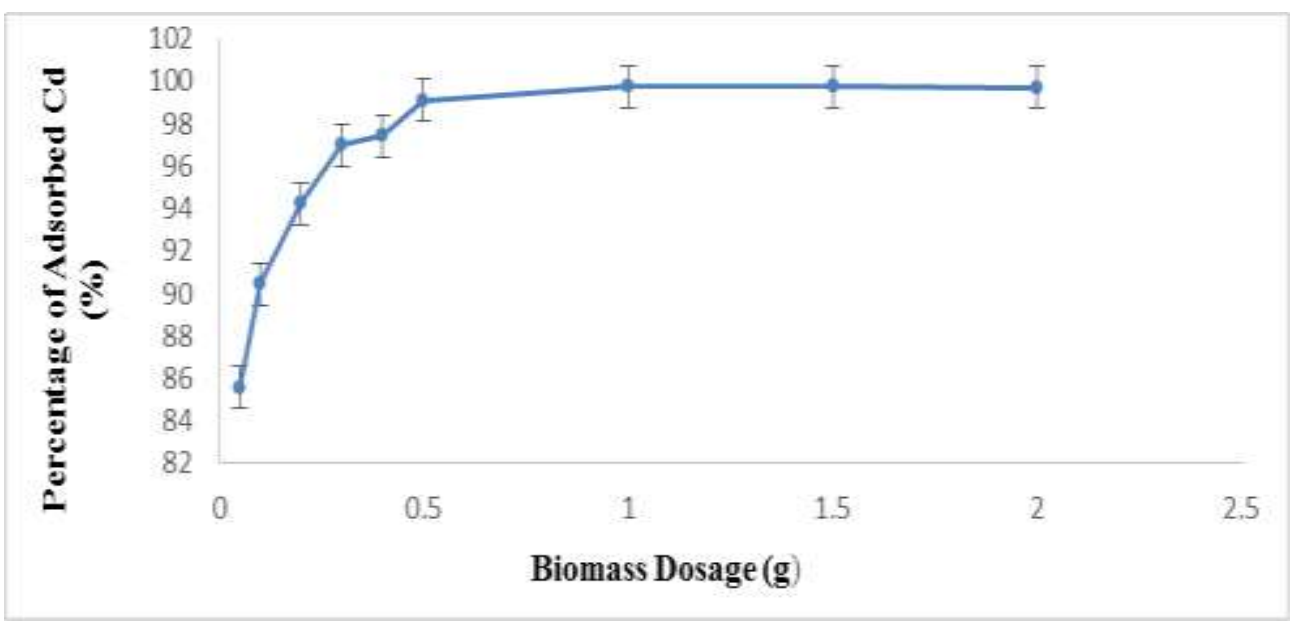

Figure 2: Effect of biosorbent dosage of Ceratophyllum demersum dry biomass on biosorption of cadmium

(Initial Cd(II) concentration $5 \mathrm{mg} / \mathrm{L}$; temperature $29{ }^{\circ} \mathrm{C}$; contact time 180 minutes; shaking speed $80 \mathrm{rpm} ; \mathrm{pH}$ 5.0)

A similar result has been reported for biosorption of cadmium on to $H$. verticillata where the saturation level reached at dosage higher than $0.1 \mathrm{~g}$ (Huang et al., 2009).

\section{Effect of Contact Time}

The influence of contact time on biosorption of $\mathrm{Cd}$ (II) ions on to Ceratophyllum demersum at $29^{\circ} \mathrm{C}$ is shown in Figure 3.

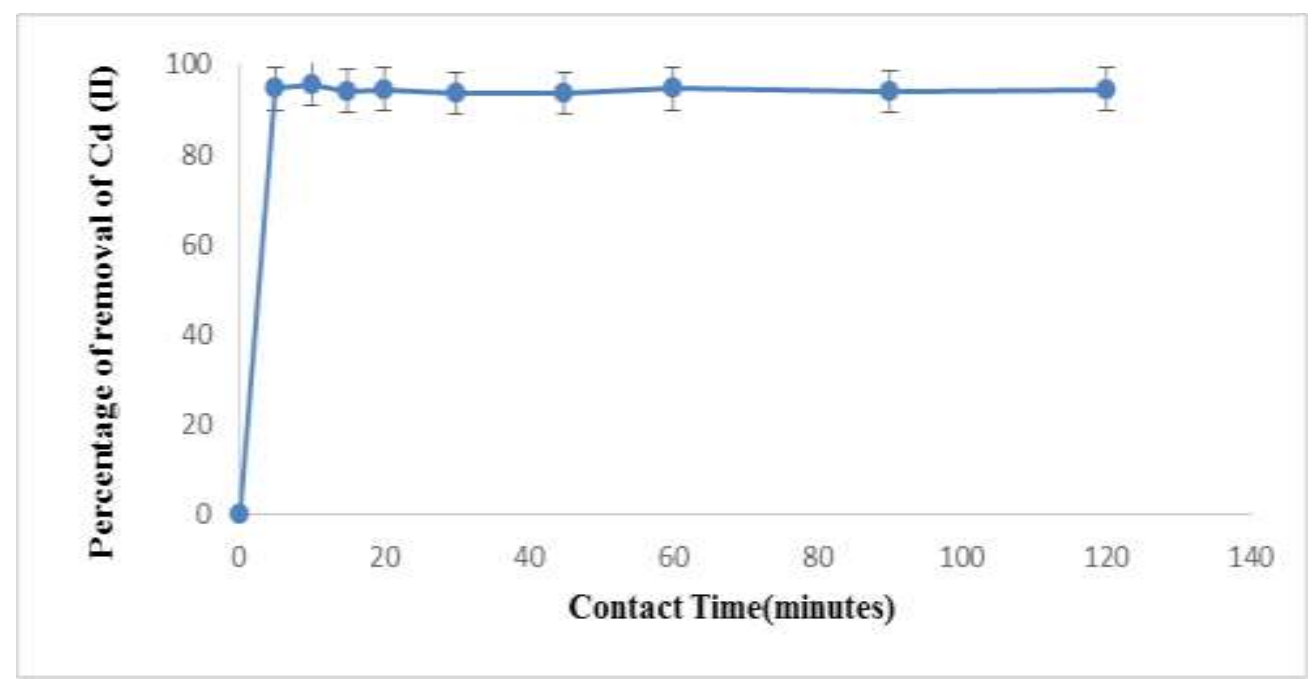

Figure 3: Effect of contact time on adsorption of cadmium (II) on to Ceratophyllum demersum

(Initial Cd (II) concentration $5.0 \mathrm{mg} / \mathrm{L}$; temperature $29{ }^{\circ} \mathrm{C}$; biomass dosage $0.5 \mathrm{~g}$ and $\mathrm{pH}$ 5; shaking speed $80 \mathrm{rpm}$ ) 
The contact time is one of the important parameters affecting the biosorption process. It is very useful to design a successful biosorption system. A very rapid metal uptake occurred within 10 minutes of contact time and the sorption process reached equilibrium by a period of 20 minutes in which the adsorption of $\mathrm{Cd}$ was $95 \%$ at $\mathrm{pH} 5$.

A similar result had been reported by Yoonaiwong et al. (2011), where Utricularia aurea which showed a rapid uptake of $\mathrm{Cd}$ within 5 minutes and equilibrium was reached within 80 minutes.

\section{Effect of Initial Concentration}

The extent of removal of heavy metals from aqueous solution depends on the initial concentration. Adsorption capacity of Ceratophyllum demersum for $\mathrm{Cd}$ adsorption at various initial concentrations of $\mathrm{Cd}$ is given in Figure 4.

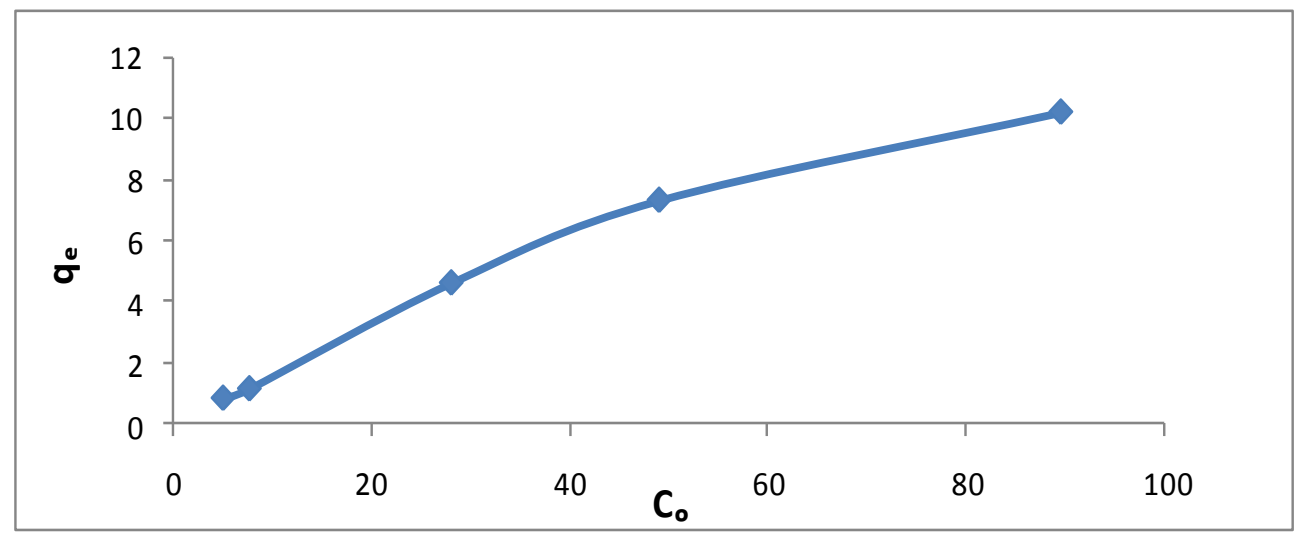

Figure 4: Effect of initial concentration of $\mathrm{Cd}$ on removal efficiency by Ceratophyllum demersum

(Contact time 180 minutes; temperature $29{ }^{\circ} \mathrm{C}$; biomass dosage $2.0 \mathrm{~g}$; pH 5; shaking speed $80 \mathrm{rpm})$

Adsorption capacity increases with increasing initial concentration continuously from $8 \mathrm{mg} / \mathrm{L}$ to $90 \mathrm{mg} / \mathrm{L}$.

The sorption data was employed to non- Linear and Linear Langmuir isotherm models and the results are given below.

\section{Linear Forms of Langmuir and Freundlich Isotherm Models}

The different forms of Langmuir linear isotherm models were plotted in Figure 5-9. Table 2 shows the calculated isotherm parameters of Langmuir isotherm model. 
Journal of Environmental Professionals Sri Lanka: 2015 - Vol. 4 - No. 2 - 10-24

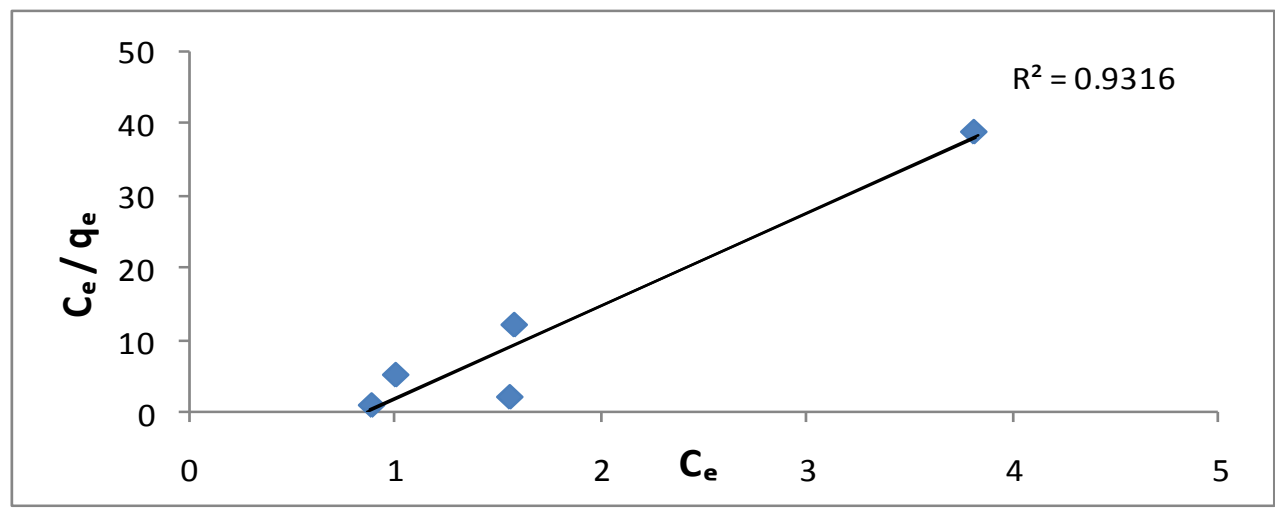

Figure 5: Langmuir model - I

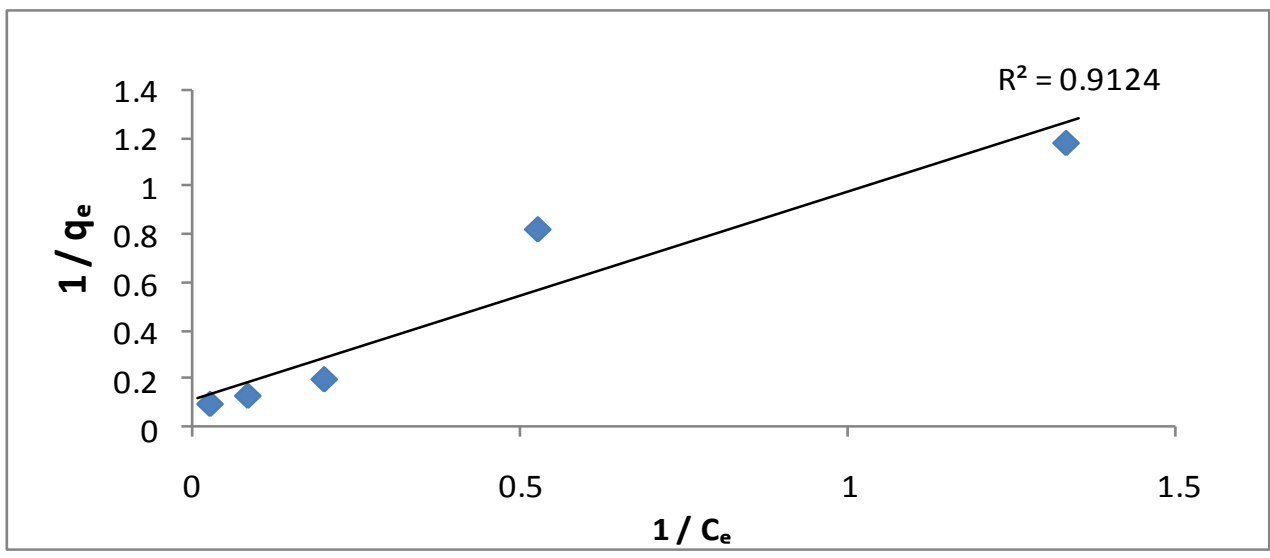

Figure 6: Langmuir model - II

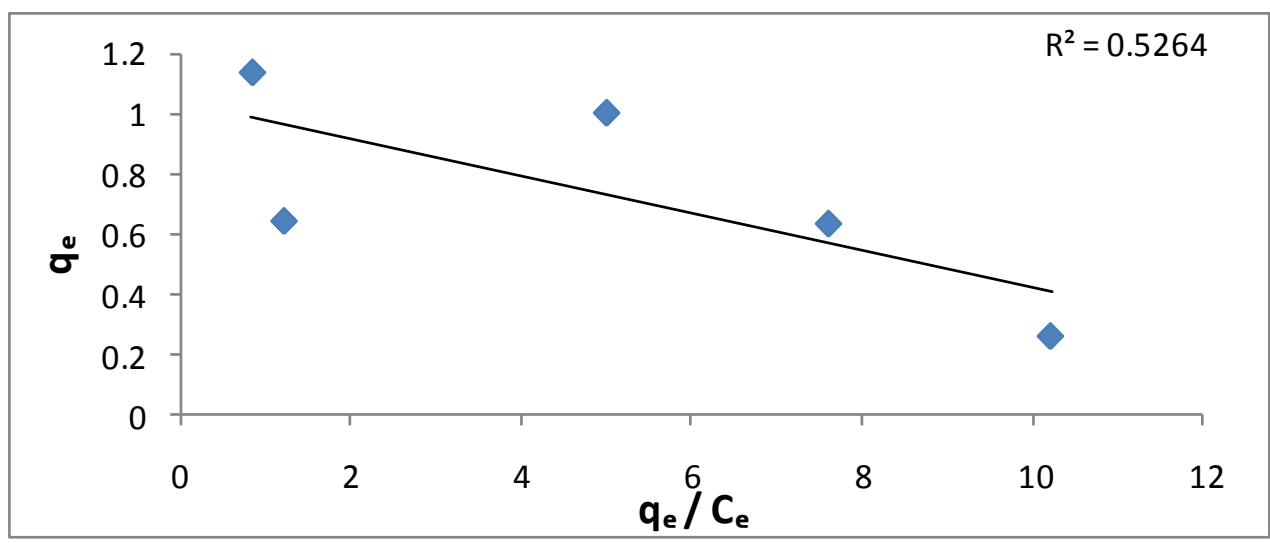

Figure 7: Langmuir model - III 


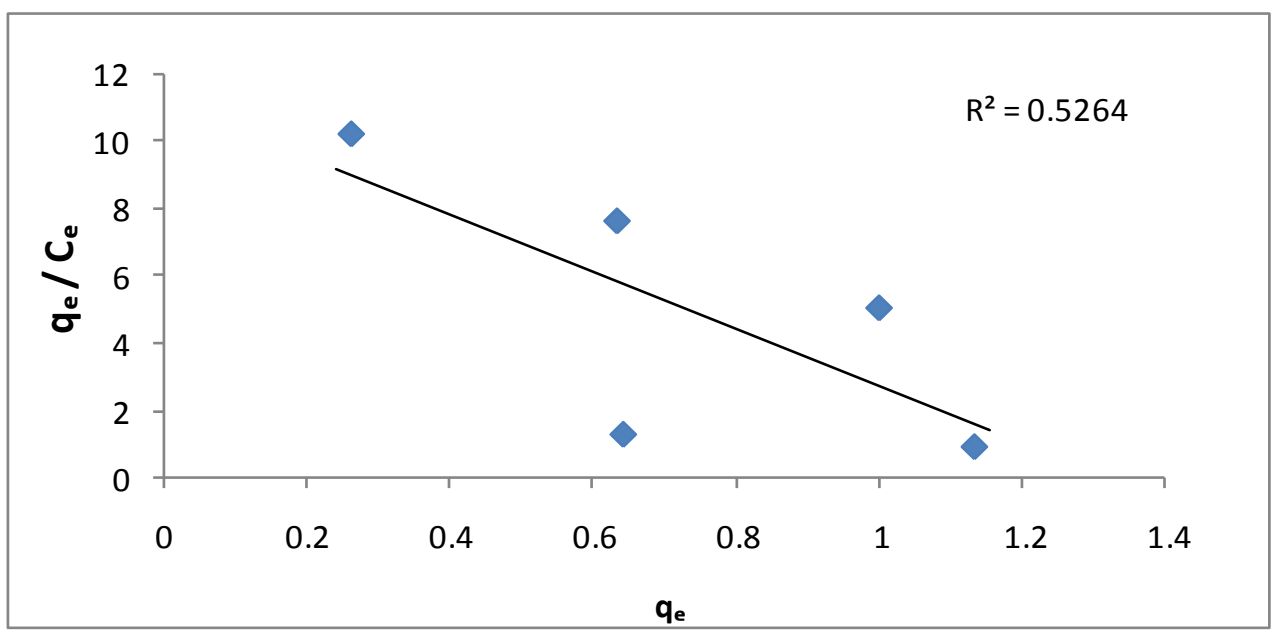

Figure 8: Langmuir model - IV

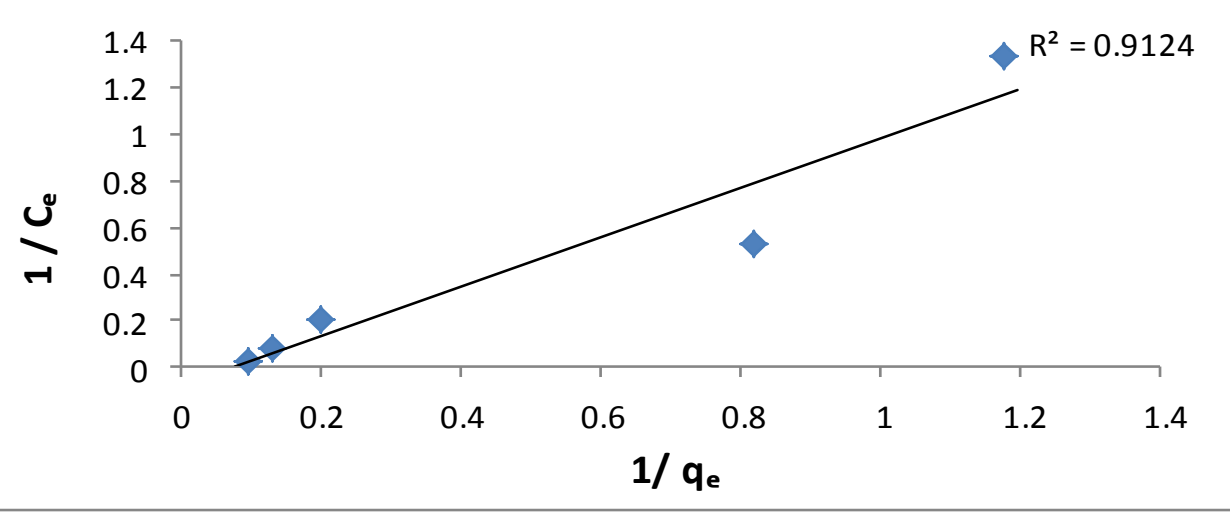

Figure 9: Langmuir model - V

Table 2. Results obtained from Linear Langmuir Isotherm model

\begin{tabular}{ccccc}
\hline Isotherm Model & $\mathbf{R}^{2}$ & $\mathbf{q m}(\mathbf{m g} / \mathbf{g})$ & $\mathbf{b}$ & $\mathbf{R}_{\mathbf{L}}$ \\
\hline Langmuir I & 0.9316 & 0.78 & -1.16 & $\mathrm{R}_{\mathrm{L}}<0$ \\
Langmuir II & 0.9124 & 8.98 & 0.13 & $\mathrm{R}_{\mathrm{L}}<0$ \\
Langmuir III & 0.5264 & 1.04 & 16.67 & $\mathrm{R}_{\mathrm{L}}<0$ \\
Langmuir VI & 0.5264 & 1.32 & 8.53 & $\mathrm{R}_{\mathrm{L}}<0$ \\
Langmuir V & 0.9124 & 13.32 & 0.08 & $\mathrm{R}_{\mathrm{L}}<0$ \\
\hline
\end{tabular}


The linear isotherm model For Freundlich isotherm was plotted in Figure 10. Table 3 shows the parameters of Freundlich Isotherm.

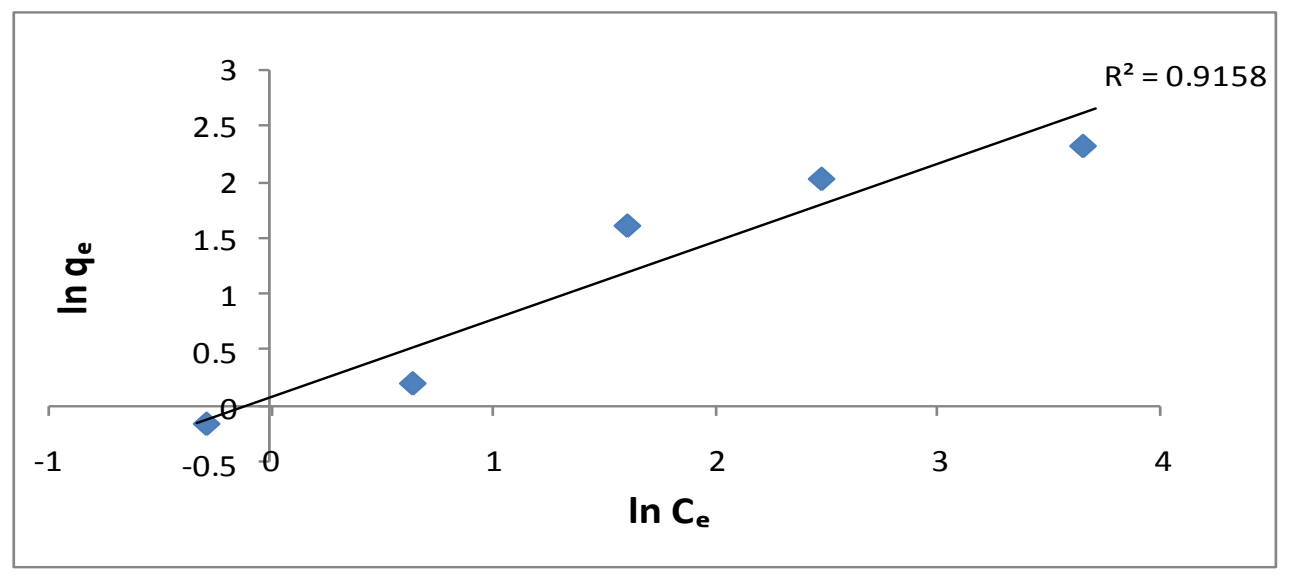

Figure 10: Freundlich Isotherm Model

Table 3. Results obtained from Linear Freundlich Isotherm model

Freundlich Isotherm Model

\begin{tabular}{ccc}
$\mathbf{K}_{\mathbf{f}}(\mathbf{L} / \mathbf{g})$ & $\mathbf{n}$ & $\mathbf{R}^{\mathbf{2}}$ \\
\hline 5.91 & 2.44 & 0.9158
\end{tabular}

The linear forms I, II, and V forms of Langmuir isotherm models have shown high correlation coefficient $\left(R^{2}=0.9316,0.9124\right)$ compared to other forms $\left(R^{2}=0.5264\right)$. However the separation factor $R_{L}$ was very low $\left(R_{L}<0\right)$ for all five types of Langmuir isotherm models. Biosorption process will be favorable where $R_{L}$ is in between 0 - 1. It is also observed that the $\mathrm{q}_{\mathrm{m}}$ value for all linearized form of Langmuir model were very low.

Linearized form of Freundlich isotherm model showed a high $\mathrm{R}^{2}$ value (0.9158) and adsorption intensity ' $\mathrm{n}$ ' was 2.44 which indicate a good adsorption.

When compared to all five forms of linearized Langmuir isotherms with linearized Freundlich isotherm, Langmuir Type I, II and $\mathrm{V}$ have higher $\mathrm{R}^{2}$ values. But Langmuir forms III and IV have same but very low $\mathrm{R}^{2}$ values compared to Freundlich isotherm model (Table 2).

Because of these different outcomes it is difficult to estimate the isotherm parameters by using only the linearized equations. Therefore nonlinear forms of both isotherm models were compared. 


\section{Non - linear form of Langmuir and Freundlich isotherm models}

Nonlinear form of Langmuir and nonlinear form Freundlich isotherm model is shown in Figure 11 and Figure 12 respectively. $\chi^{2}$ values of both models are given in Table 4.

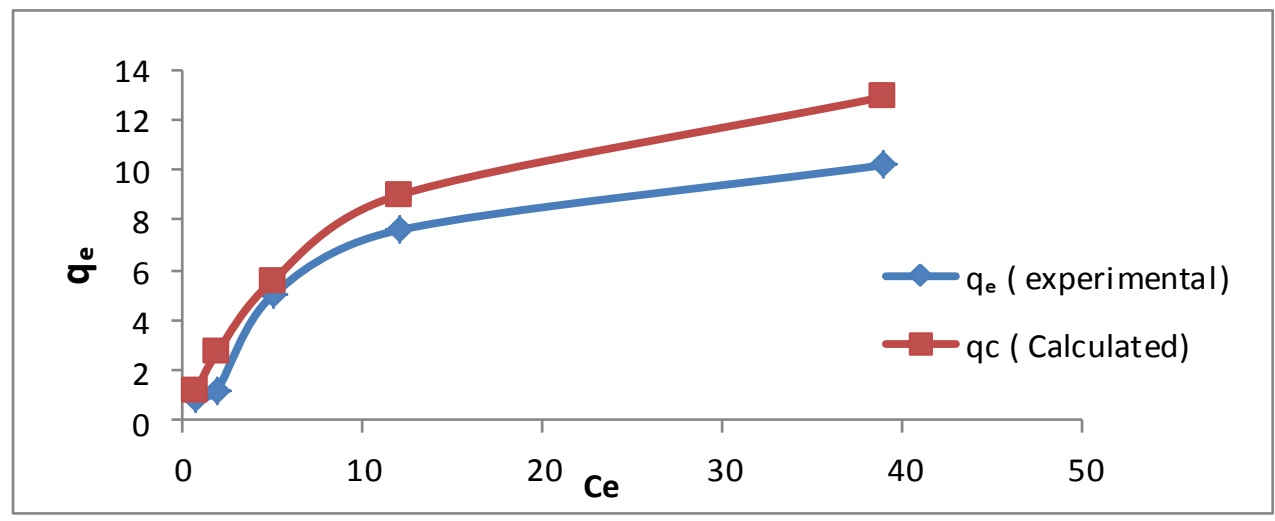

Figure 11: Nonlinear Langmuir Isotherm Model

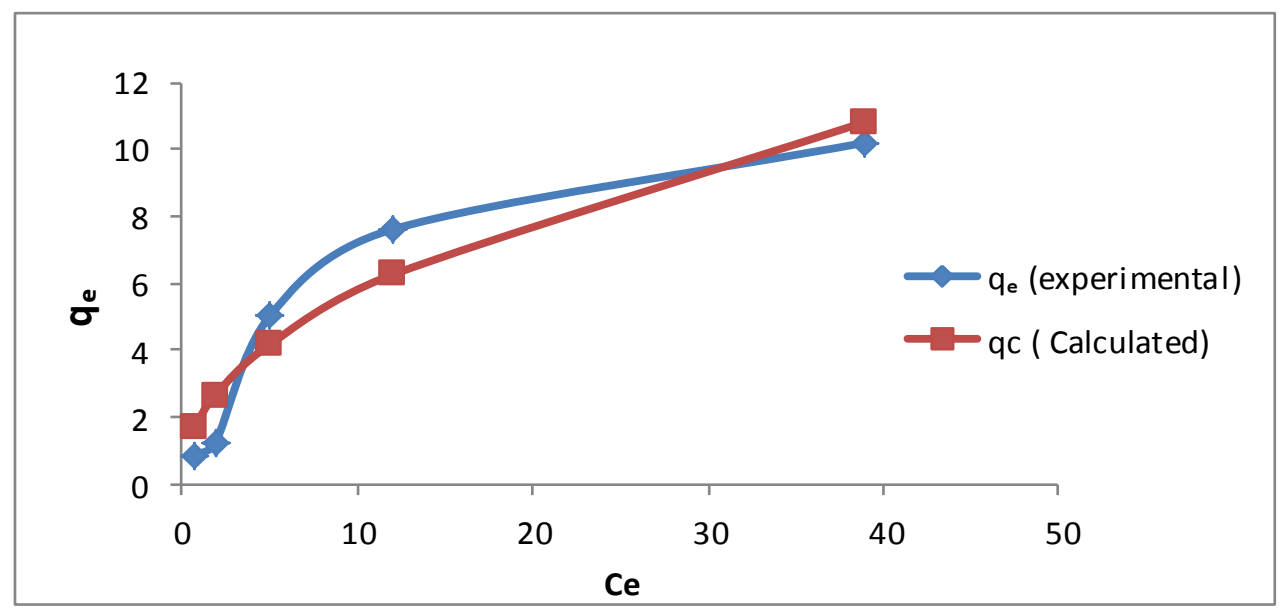

Figure 12: Nonlinear Freundlich Isotherm Model

Table 4. Results obtained from nonlinear isotherm models

\begin{tabular}{cc}
\hline Isotherm Models & $\boldsymbol{X}^{2}$ \\
\hline Langmuir Isotherm Model & 4.58 \\
Freundlich Isotherm Model & 1.95 \\
\hline
\end{tabular}


When compared $\chi^{2}$ values of both models, the low value (1.95) for $\chi^{2}$ for Freundlich isotherm suggests that this model can be used to explain the biosorption of Cd (II) from aqueous solution by the aquatic weed: Ceratophyllum demersum. (Mirjana et al., 2012)

\section{Desorption Studies}

To evaluate the efficiency and feasibility of a metal removal process, the regeneration and reversibility of the biosorbent should be considered. In this desorption study, $0.1 \mathrm{M}$ EDTA, $0.1 \mathrm{M} \mathrm{HCl}$ and $0.1 \mathrm{M} \mathrm{HNO}_{3}$ were used as the desorbing agent and the results (Figure 13) indicate that EDTA, $\mathrm{HCl}$ and $\mathrm{HNO}_{3}$ desorbed $97 \%, 94 \%$, and $85 \%$ cadmium ions respectively from the biomass.

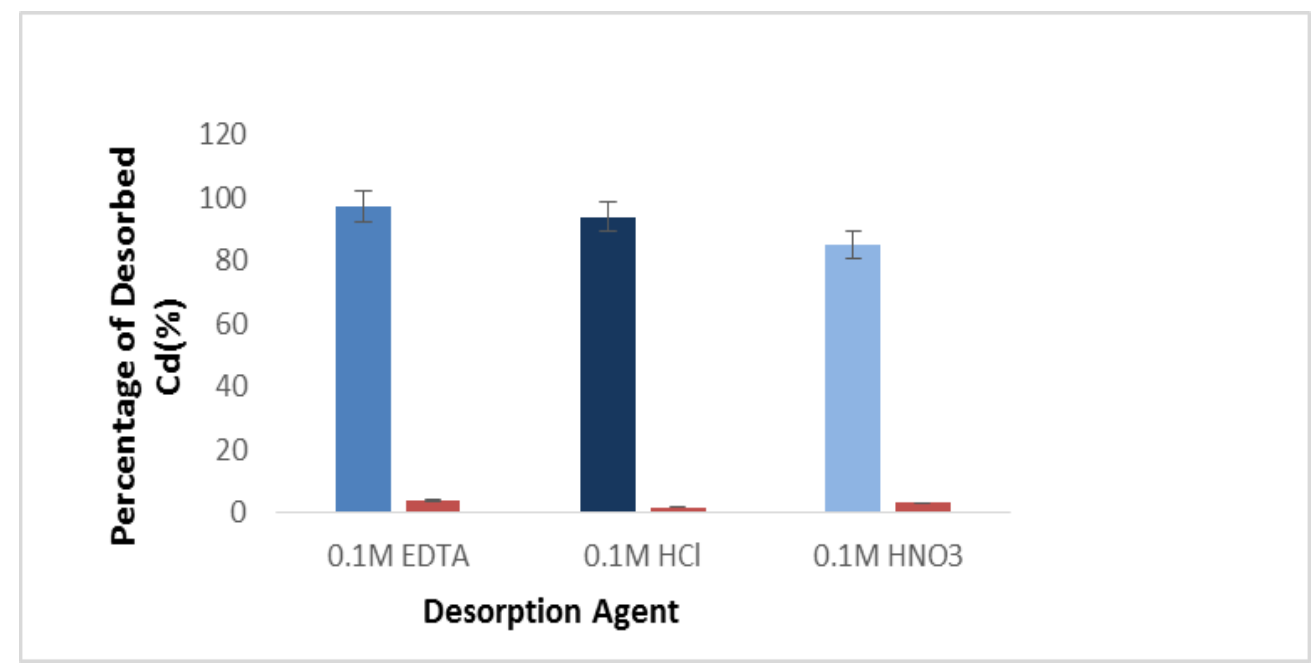

Figure 13: Percentage desorption of cadmium from Cd- loaded biomass of Ceratophyllum demersum by different desorbing agents

(Initial Cd (II) concentration $40.0 \mathrm{mg} / \mathrm{L}$; temperature $29^{\circ} \mathrm{C}$; biomass dosage $0.2 \mathrm{~g}$; pH 5 at 80 rpm; contact time - 30 minutes)

Therefore, all EDTA, $\mathrm{HNO}_{3}$ and $\mathrm{HCl}$ could be used as desorbents for cadmium ions.

\section{Conclusion}

Non-living biomass of Ceratophyllum demersum is a good biosorbent for removing $\mathrm{Cd}$ (II) from aqueous solution.

Batch adsorption experiments showed that the adsorption of cadmium from aqueous solution is very rapid. The maximum percentage removal was $95 \%$ by $1.0 \mathrm{~g}$ of biomass at $\mathrm{pH} 5$ such adsorption reached the equilibrium by 20 minutes. The adsorption of cadmium increases with increasing dosage of biosorbent. Cadmium 
ions adsorbed on Ceratophyllum demersum were effectively desorbed by $0.1 \mathrm{M}$ EDTA (97\%), $0.1 \mathrm{M} \mathrm{HCl}(94 \%)$ and $0.1 \mathrm{M} \mathrm{HNO}_{3}(85 \%)$, which shows that adsorbed cadmium can be recovered from the loaded biomass.

Equilibrium studies showed that Freundlich isotherm model relatively showing better fit with the sorption data, which suggests a multilayer adsorption.

\section{Acknowledgements}

Authors wish to thank the faculty of Natural Sciences of the Open University of Sri Lanka for financial support (Faculty Research Grant 2013).

\section{References}

Ahalya, N., T. V. Ramachandra and R. D. Kanamadi (2003). "Biosorption of heavy metals". Res. J. Chem. Environment, 7(4).

Chathuranga, P. K. D., N. Priyantha, S. S. Iqbal, M. C. M. Iqbal (2012). "Biosorption of Cr (III) and Cr (VI) species from aqueous solution by Cabomba caroliniana: Kinetic and equilibrium study". Environ. Earth Sci., 1866-6280.

Dada, A. O., A. P. Olalekan and A. M. Olatunya (2012). "Langmuir, Freundlich, Temkin and Dubinin-Radushkevich Isotherms Studies of Equilibrium Sorption of $\mathrm{Zn}^{2+}$ onto Phosphoric Acid Modified Rice Husk". Journal of Applied Chemistry, 3: 38-45.

Esfahani, A. M., A. F. Firouzi, G. Sayyad and A. Kiasat (2013). "Isotherm study of Cadmium Adsorption onto Stabilized - Zerovalent Iron nano particles". 4(12): 34443454.

Hoenig, M., H. Baeten, S. Vanhentenrijk, E. Vassileva and Ph. Quevauviller (1998). "Critical discussion on the need for an efficient mineralization procedure for the analysis of plant material by atomic spectrometric methods". Analytica Chimica ACTA, 358(1): 85- 94.

Huang, L., D. Huang and Z. Ling (2009). "Biosorption of cadmium (II) from aqueous solution to H. verticillata". Environment and Earth Sci., 60: 1683-1691.

Mirjana, M. B., A. T. Aleksander, B. S. Marina and Z. R. Dusan (2012). "Isotherms for the adsorption of $\mathrm{Cu}$ (II) onto lignin - Comparison of linear and non - linear methods". Hem. Ind., 66(4): 497-503.

Pérez-Marín, A. B., V. Meseguer Zapata, J. F. Ortuño, M. Aguilar, J. Sáez and M. Lloréns (2007). "Removal of cadmium from aqueous solutions by adsorption onto orange waste". Journal of Hazardous Materials, 139(1): 122-131.

Pinoa, G. H., L. M. S. Mesquitaa, M. L. Torema and G. A. S. Pintob (2006). "Biosorption of Heavy Metals by Powder of Green Coconut Shell”. 41(14): 3141-3153. 
Radojevic, M. and V. N. Baski (2006). "Practical Environmental Analysis". The Royal Society of Chemistry, Cambridge, UK.

Sutherland, C. and C. Venkobachar (2013). "Equilibrium modeling of Cu (II) biosorption onto untreated and treated forest macro fungus Fomes fasciatus". International Journal of Plant, Animal and Environmental Sciences, 3(1): 193-203.

Volesky, B. and G. Naja (2007). "Biosorption technology: Starting up an enterprise". Int. J. Technology Transfer \& Commercialization, 6(2/3/4): 196-211.

Witek, K. A., R. G. Szafra and S. Modelski (2011). "Biosorption of heavy metals from aqueous solutions onto peanut shell as a low-cost biosorbent". 265: 126-134.

Yoonaiwong, W., P. Kaewsarn and P. Reanprayoon (2011). "Biosorption of lead and cadmium ions by non-living aquatic macrophyte Utricularia aurea". Sustainable Environmental Resource, 21(6): 369-374. 